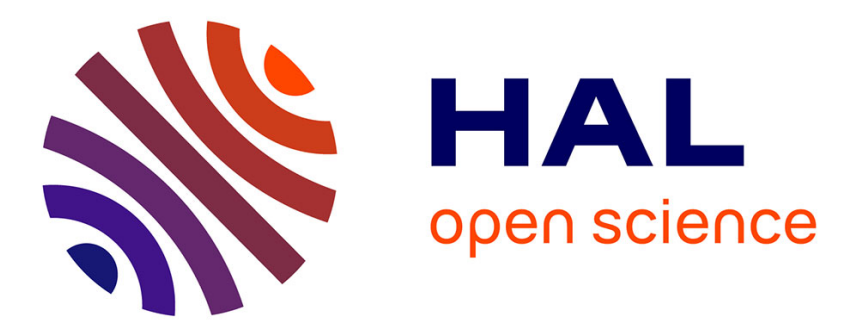

\title{
Infrared spectroscopy and multivariate analysis to appraise alpha-cellulose extracted from wood for stable carbon isotope measurements
}

Béatrice Richard, Fabienne Quilès, Cedric Carteret, Oliver Brendel

\section{- To cite this version:}

Béatrice Richard, Fabienne Quilès, Cedric Carteret, Oliver Brendel. Infrared spectroscopy and multivariate analysis to appraise alpha-cellulose extracted from wood for stable carbon isotope measurements. Chemical Geology, 2014, 381, pp.168-179. 10.1016/j.chemgeo.2014.05.010 . hal-01503746

\section{HAL Id: hal-01503746 \\ https://hal.univ-lorraine.fr/hal-01503746}

Submitted on 27 May 2020

HAL is a multi-disciplinary open access archive for the deposit and dissemination of scientific research documents, whether they are published or not. The documents may come from teaching and research institutions in France or abroad, or from public or private research centers.
L'archive ouverte pluridisciplinaire HAL, est destinée au dépôt et à la diffusion de documents scientifiques de niveau recherche, publiés ou non, émanant des établissements d'enseignement et de recherche français ou étrangers, des laboratoires publics ou privés.

\section{(2)(1) $\$$}

Distributed under a Creative Commons Attribution - NonCommercial - ShareAlikel 4.0 
B. Richard et al. / Chemical Geology 381 (2014) 168-179

\title{
Infrared spectroscopy and multivariate analysis to appraise $\alpha$ - cellulose extracted from wood for stable carbon isotope measurements
}

\author{
Béatrice Richard $^{\mathrm{a}, \mathrm{b}^{*}}$, Fabienne Quilès ${ }^{\mathrm{c}, \mathrm{d} \#}$, Cédric Carteret $^{\mathrm{c}, \mathrm{d}}$, and Oliver Brendel ${ }^{\mathrm{a}, \mathrm{b}}$

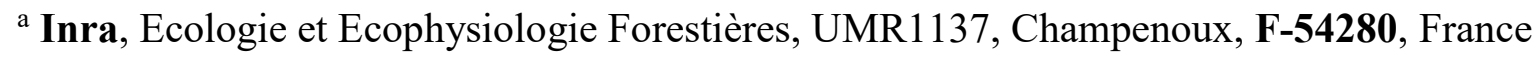 \\ ${ }^{\mathrm{b}}$ Université de Lorraine, Ecologie et Ecophysiologie Forestières, UMR1137, Vandœuvre-lès- \\ Nancy, F-54500, France \\ ${ }^{\mathrm{c}}$ CNRS, Laboratoire de Chimie Physique et Microbiologie pour l'Environnement, UMR 7564, \\ Villers-lès-Nancy, F-54600, France. \\ d Université de Lorraine, Laboratoire de Chimie Physique et Microbiologie pour \\ l’Environnement, UMR 7564, Villers-lès-Nancy, F-54600, France.
}

\section{Some practical details for the cellulose extraction method}

Before beginning the chemical extractions, the powdered wood samples are oven dried at $60^{\circ} \mathrm{C}$ for $24 \mathrm{~h}$. Then, $0.15 \mathrm{~g}$ of the sample material is put into individual pouches made of PFTE pre-cut filter membranes with a pore size of $1 \mu \mathrm{m}$ (Alltech, France). The filter membrane is shaped into a pouch which are closed with a Teflon ribbon and identified with coloured glass beads on the ribbon ("sample pouches"). For several steps of the $\alpha$-cellulose extraction process (Fig. 1 in the published article), samples are put in an ultrasound water bath at $45 \mathrm{~Hz}$ (VWR cleaner) ("ultrasound bath"). The quantities in the following method description were used for sample pouches containing each $0.15 \mathrm{~g}$ of dry wood material and a number of pouches according to the glassware used in each step. Quantities of solvents and products need to be adjusted to other sample quantities.

(1) Extractives free. One hundred and twenty sample pouches are placed in three Soxhlet extractors (around 40 sample pouches, thus together $6 \mathrm{~g}$ of wood material in a $125 \mathrm{~mL}$ extractor bulb) with each a 2:1 (v/v) 95\% toluene: 95\% ethanol mixture (for 5 successive cycles) and then with 99.8\% ethanol (for 3 successive cycles). Sample pouches are then removed and placed in $99.8 \%$ ethanol and subjected to the "ultrasound bath" at room temperature for 10 minutes. Then, the sample pouches are removed from the ethanol bath, put on a flat surface under a fume hood for one hour to remove the solvents. Next, the same sample pouches are boiled in distilled water into two beaker each containing $1 \mathrm{~L}$ of distilled water ( $\sim 00$ pouches in each beaker). Each beaker is covered with watch glass and placed into a water bath for 3 hours followed by the "ultrasound bath" at room temperature for 10 minutes in warm distilled water.

(2) $\mathrm{NaClO} 2$ delignification. The sample pouches are then transferred into two Erlenmeyer flask each containing $800 \mathrm{~mL}$ of distilled water ( $\sim 60$ pouches representing $9 \mathrm{~g}$ of original wood material), where the $\mathrm{pH}$ value 
is adjusted between 3 and 4 by adding glacial acetic acid. Then, the lignin digestion is started by adding $21 \mathrm{~g}$ of $\mathrm{NaClO}_{2}(\approx 2.45 \mathrm{~g} / \mathrm{g}$ of wood $)$ to each flask. These flasks are placed on a hot plate at $70^{\circ} \mathrm{C}$, and solutions are shaken under magnetic stirrer for 14 hours, to enable a complete penetration of the liquid into the sample pouches. The flasks are covered to allow vapour condensing, but not tightly, to avoid a pressure increase. Then the flasks containing the sample pouches are moved to the "ultrasound bath" at $70^{\circ} \mathrm{C}$ till the end of the experiment. Subsequently, depending on the chemical treatment performed (Table 1 in the published article and see published article for data for oak, beech, pine and poplar), one and up to four more additions of $21 \mathrm{~g}$ of $\mathrm{NaClO}_{2}$ are made to each Erlenmeyer flasks, with a time of two hours between every addition. Before each addition of $\mathrm{NaClO}_{2}$, the $\mathrm{pH}$ value is adjusted to values between 3 and 4 by adding glacial acetic acid. Two hours after the last addition of $\mathrm{NaClO}_{2}$, the sample pouches are removed and washed once with $1 \mathrm{~L}$ of distilled water in a beaker subjected to the "ultrasound bath" at room temperature for 10 minutes, then washed for 14 hours with $2 \mathrm{~L}$ of distilled water in a beaker using a magnetic stirrer and again during one hour under continuous fresh distilled water flow in a $2 \mathrm{~L}$ side-arm flask. If this state of cellulose extraction (usually called holocellulose) is sufficient, the sample pouches are removed from the distilled water, dried with $99.8 \%$ ethanol in a beaker in the "ultrasound bath" at room temperature for 10 minutes. Sample pouches are removed from ethanol and put on a flat surface for mechanically dried under a fume hood for several hours, then opened, and the extracted cellulose is transferred to Eppendorf sampling tubes, in which the samples are dried (at least $36 \mathrm{~h}$ for complete dryness) in an oven at $60^{\circ} \mathrm{C}$.

(3) Alkaline $\mathrm{NaOH}$ hydrolysis. To achieve analytical $\alpha$-cellulose (substract some residual hemicelluloses) an additional step of alkaline hydrolysis is sometimes necessary (see published article for data for oak, beech, pine and poplar). To avoid the formation of carbonates from atmospheric $\mathrm{CO}_{2}$ dissolved in the sodium hydroxide solution, all $\mathrm{NaOH}$ solution preparation steps are placed under "ultrasonic bath". Step one: a beaker with 1L of distilled water is already subjected to the "ultrasonic bath" for $5 \mathrm{~min}$, prior to adding the soda. Step two: always under "ultrasonic bath" appropriate sodium hydroxide pellet according to required $10 \%$ of sodium hydroxide solution is added in the beaker. Step three: $5 \mathrm{~min}$ after the soda addition, the sample pouches are introduced in sodium hydroxide solution to react under "ultrasonic bath" for 1 hour (each beaker containing $~ 60$ pouches representing $9 \mathrm{~g}$ of original wood material). The sample pouches are then removed from the beaker and washed once with $1 \mathrm{~L}$ of distilled water in a beaker subjected to the "ultrasound bath" for $10 \mathrm{~min}$. Next, the sample pouches are placed in $1 \mathrm{~L}$ of distilled water and the $\mathrm{pH}$ is adjusted to $7-8$ using $10 \%$ hydrochloric acid solutions under "ultrasound bath" for $30 \mathrm{~min}$.

The sample pouches are then removed and washed thrice with $1 \mathrm{~L}$ of distilled water in a beaker subjected to the "ultrasound bath" for $10 \mathrm{~min}$, They are dried with $99.8 \%$ ethanol in a beaker subjected to the "ultrasound bath" for $10 \mathrm{~min}$ and then under a hood with ventilated air to several hours. Then, the samples pouches are opened and the extracted cellulose is removed from the pouches and oven-dried in $1 \mathrm{ml}$ Eppendorf tubes at $60^{\circ} \mathrm{C}$ for $36 \mathrm{~h}$. 